\title{
Obesity and Breast Cancer: A Multipartite Connection
}

\author{
Dipali Sharma • Nancy E. Davidson
}

Received: 23 October 2013 / Accepted: 24 October 2013 /Published online: 5 November 2013

(C) Springer Science+Business Media New York 2013

It is our great pleasure to provide a brief introduction to this special issue of the Journal of Mammary Gland Biology and Neoplasia that is devoted to obesity and breast cancer. This issue contains reviews discussing the impact of obesity on breast cancer and dissecting the underlying molecular networks that, in our opinion, represent key pathways mediating the effects of obese state on breast carcinogenesis. In the last few years, basic science has advanced to the point where innovative tools have been developed to study and target the key nodes of obesity-breast cancer link; these models and emerging therapeutic targets will be discussed.

This is a very timely issue. The prevalence of overweight and obesity has dramatically increased in the last two decades in the United States and many other countries. Notably, obesity is second only to tobacco as a leading risk factor for cancer and nearly $30 \%$ of cancers are attributable to obesity. The association of obesity with breast cancer has been examined in multiple studies. It is now known that obesity is not only a risk factor for the increased tumor aggressiveness, poorer prognosis, higher rate of recurrence and poorer survival of obese breast cancer patients, but it also affects the development of new cases of breast cancer. A recent meta-analysis examining the effect of obesity on survival of women with breast cancer reported a hazard ratio (HR) of $1.30-1.35$ for mortality in obese vs. non-obese subjects [1].

\footnotetext{
D. Sharma $(\bowtie)$

Department of Oncology and the Sidney Kimmel Comprehensive Cancer Center, Johns Hopkins University School of Medicine, 1650 Orleans Street, CRB 1, Rm 145, Baltimore, MD 21231, USA e-mail: dsharma7@jhmi.edu

N. E. Davidson $(\square)$

University of Pittsburgh Cancer Institute and UPMC Cancer Center, UPMC Cancer Pavilion, 5150 Centre Avenue, Suite 500, Pittsburgh, PA 15232, USA

e-mail: davidsonne@upmc.edu
}

Obesity at time of diagnosis was also found to be associated with a greater than two-fold increased risk of breast cancer recurrence (HR 2.43) [2]. Multiple clinical studies have been conducted to examine the factors that play a role in mediating the impact of obesity on breast cancer outcomes.

Obesity is a complex physiologic state that is associated with multiple molecular changes capable of modulating tumor cell behavior as well as aspects of the surrounding microenvironment. Gene expression analysis of breast tumors from normal, overweight and obese breast cancer patients revealed an obesity-associated breast cancer transcriptional gene signature which correlated with worse patient outcome when analyzed using various public expression data sets [3]. Obese state appears to modulate gene expression patterns of the tumor cells, potentially altering their growth and metastatic potential. Multiple factors in the breast tumor microenvironment can influence breast tumor cells. Size heterogeneity of normal adipocytes is often lost in obesity in favor of adipocyte hypertrophy (increase in cell size) and hyperplasia (increase in cell number). Increased number of hypertrophied adipocytes may produce increased levels of hormones (e.g., estrogen) to promote aggressive behavior of tumor cells [4]. Additionally, increased numbers of infiltrating TNF $\alpha$ and interleukin (IL)-6 secreting macrophages, endothelial cells, T-cells, mast cells and other immune cells in the tumor microenvironment alter tumor behavior in obese conditions $[5,6]$.

Hyperinsulinemia associated with obesity promotes the biological activity of insulin-like growth factor-1 (IGF-1) and alters the levels and activity of proinflammatory cytokines, chemokines and adipokines [7] leading to breast tumor progression and metastasis. Epidemiological studies have shown a strong relationship between high levels of circulating insulin and c-peptide and poor prognosis of breast cancer [8,9]. Various studies of different populations, genders and age groups have found a non-linear relationship 
between circulating concentrations of IGF-1 and increased BMI (reviewed in [10]) and high IGF-1 levels positively correlate with increased breast cancer risk [11, 12]. IGF-1 overexpression leads to excessive proliferation and increased survival signals for the development of breast tumors [13]. In fact, inactivation of IGF-1R results in reduced breast tumor growth and metastasis in vivo [14]. It is noteworthy that IGF-1R is overexpressed in $\sim 50 \%$ of primary breast tumors compared with normal tissue indicating that these carcinomas may have enhance responses to the mitogenic and anti-apoptotic effects of IGF-1 in their immediate obese microenvironment [15].

The cytokine profile associated with obesity is typically altered to show a reduction in the release of anti-inflammatory factors and an increase in the secretion of pro-inflammatory factors, which might thereby trigger a chronic inflammation state $[16,17]$. In recent years, the presence of chronic inflammation in obese women, characterized by increased levels of C-reactive protein, inflammatory cytokines (TNF $\alpha$, IL-6, IL-8 and monocyte chemoattractant MCP-1) and leptin, has gained increased attention as it creates a tumor-supporting inflammatory milieu [18]. Importantly, local adipose inflammation, manifesting as inflammatory foci known as crown-like structures (CLS) consisting of dead adipocytes encircled by macrophages, is observed in breast tissue of most overweight and obese women. In a feed-forward manner, saturated fatty acids are released as a result of obesityassociated lipolysis to induce macrophage activation via Tolllike receptor 4 and NF-kB activation [19]. These proceedings lead to activation of inflammatory cytokines (TNF $\alpha$, IL-6, IL8 ) triggering a series of events in the inflammatory process. In addition, induction of cyclooxygenase-2 (COX-2) and prostaglandin (PG) expression as a consequence of inflammation can induce aromatase expression and estrogen synthesis, further supporting breast cancer cell growth and metastatic behavior.

An additional player has been identified as a key member of the obesity-molecular network that influences several components of microenvironment as well as growth and metastatic characteristics of breast cancer cells: the adipokine, leptin. Over the last few years, multiple epidemiological studies have linked high levels of plasma leptin with increased risk and poor prognosis for breast carcinogenesis [20-24]. Circulating as a $16-\mathrm{kD}$ protein, partially bound to plasma proteins, leptin exerts its biological actions through specific cell surface receptors (leptin receptors) present in a variety of tissues [25]. Breast carcinoma cells express higher levels of leptin receptor in comparison to normal mammary epithelial cells, allowing cancer cells to acquire increased sensitivity to leptin in the tumor microenvironment. Overexpression of leptin is observed in $92 \%$ of breast tumors whereas little or no expression of leptin is found in normal mammary epithelial cells [26]. Thus, in obese conditions, leptin affects breast cancer growth via endocrine, paracrine and autocrine interactions.

With the rising obesity pandemic, its newly acquired designation as a "disease" and its strong impact on breast cancer incidence, behavior, and prognosis, it is important to understand the clinical and molecular links underlying the obesity-breast cancer connection. In this issue, experts succinctly review our current understanding of obesity-breast cancer related molecular pathways, taking into account the role of various secreted factors and microenvironment components. They also review the clinical implications of these studies, presenting the in vivo models that have proven invaluable in obesity research and discussing potential therapeutic tools to break the obesity-breast cancer connection. Our goal in assembling this issue is to provide insight into the obesitybreast cancer link at the preclinical and clinical levels, identify gaps in our knowledge and most importantly, inspire others to join us in studying the multiple faces of obesity as it impacts breast cancer.

Conflict of Interest No potential conflicts of interest were disclosed.

Financial Support NCI NIH R01CA131294, Avon Foundation (to DS) and Breast Cancer Research Foundation (to DS and NED).

\section{References}

1. Protani M, Coory M, Martin JH. Effect of obesity on survival of women with breast cancer: systematic review and meta-analysis. Breast Cancer Res Treat. 2010;123:627-35.

2. Kamineni A, Anderson ML, White E, Taplin SH, Porter P, BallardBarbash R, et al. Body mass index, tumor characteristics, and prognosis following diagnosis of early-stage breast cancer in a mammographically screened population. Cancer Causes Control. 2013;24:305-12.

3. Creighton CJ, Sada YH, Zhang Y, Tsimelzon A, Wong H, Dave B, et al. A gene transcription signature of obesity in breast cancer. Breast Cancer Res Treat. 2012;132:993-1000.

4. Manabe Y, Toda S, Miyazaki K, Sugihara H. Mature adipocytes, but not preadipocytes, promote the growth of breast carcinoma cells in collagen gel matrix culture through cancer-stromal cell interactions. J Pathol. 2003;201:221-8.

5. Weisberg SP, McCann D, Desai M, Rosenbaum M, Leibel RL, Ferrante Jr AW. Obesity is associated with macrophage accumulation in adipose tissue. J Clin Invest. 2003;112:1796-808.

6. Place AE, Jin Huh S, Polyak K. The microenvironment in breast cancer progression: biology and implications for treatment. Breast Cancer Res. 2011;13:227.

7. Pollak M. Insulin and insulin-like growth factor signalling in neoplasia. Nat Rev Cancer. 2008;8:915-28.

8. Goodwin PJ, Ennis M, Pritchard KI, Trudeau ME, Koo J, Madarnas $\mathrm{Y}$, et al. Fasting insulin and outcome in early-stage breast cancer: results of a prospective cohort study. J Clin Oncol. 2002;20:42-51.

9. Dankner R, Shanik MH, Keinan-Boker L, Cohen C, Chetrit A. Effect of elevated basal insulin on cancer incidence and mortality in cancer incident patients: the Israel GOH 29-year follow-up study. Diabetes Care. 2012;35:1538-43. 
10. Renehan AG, Harvie M, Howell A. Insulin-like growth factor (IGF)I, IGF binding protein-3, and breast cancer risk: eight years on. Endocr Relat Cancer. 2006;13:273-8.

11. Muti P, Quattrin T, Grant BJ, Krogh V, Micheli A, Schunemann HJ, et al. Fasting glucose is a risk factor for breast cancer: a prospective study. Cancer Epidemiol Biomarkers Prev. 2002;11:1361-8.

12. Zhang X, Yee D. Tyrosine kinase signalling in breast cancer: insulinlike growth factors and their receptors in breast cancer. Breast Cancer Res. 2000;2:170-5.

13. Pacher M, Seewald MJ, Mikula M, Oehler S, Mogg M, Vinatzer U, et al. Impact of constitutive IGF1/IGF2 stimulation on the transcriptional program of human breast cancer cells. Carcinogenesis. 2007;28:49-59.

14. Sachdev D, Hartell JS, Lee AV, Zhang X, Yee D. A dominant negative type I insulin-like growth factor receptor inhibits metastasis of human cancer cells. J Biol Chem. 2004;279:5017-24.

15. Shimizu C, Hasegawa T, Tani Y, Takahashi F, Takeuchi M, Watanabe $\mathrm{T}$, et al. Expression of insulin-like growth factor 1 receptor in primary breast cancer: immunohistochemical analysis. Hum Pathol. 2004;35: $1537-42$.

16. Hoene $M$, Weigert $C$. The role of interleukin- 6 in insulin resistance, body fat distribution and energy balance. Obes Rev. 2008;9:20-9.

17. Hovey RC, Aimo L. Diverse and active roles for adipocytes during mammary gland growth and function. J Mammary Gland Biol Neoplasia. 2010;15:279-90.

18. Zeyda M, Stulnig TM. Obesity, inflammation, and insulin resistancea mini-review. Gerontology. 2009;55:379-86.
19. Howe LR, Subbaramaiah K, Hudis CA, Dannenberg AJ. Molecular Pathways: adipose inflammation as a mediator of obesity-associated cancer. Clin Cancer Res. 2013

20. Wu MH, Chou YC, Chou WY, Hsu GC, Chu CH, Yu CP, et al. Circulating levels of leptin, adiposity and breast cancer risk. Br J Cancer. 2009;100:578-82.

21. Garofalo C, Koda M, Cascio S, Sulkowska M, Kanczuga-Koda L, Golaszewska J, et al. Increased expression of leptin and the leptin receptor as a marker of breast cancer progression: possible role of obesity-related stimuli. Clin Cancer Res. 2006;12:1447-53.

22. Snoussi K, Strosberg AD, Bouaouina N, Ben Ahmed S, Helal AN, Chouchane L. Leptin and leptin receptor polymorphisms are associated with increased risk and poor prognosis of breast carcinoma. BMC Cancer. 2006;6:38.

23. Irwin ML, McTiernan A, Bernstein L, Gilliland FD, Baumgartner R, Baumgartner K, et al. Relationship of obesity and physical activity with C-peptide, leptin, and insulin-like growth factors in breast cancer survivors. Cancer Epidemiol Biomarkers Prev. 2005;14:2881-8.

24. Han C, Zhang HT, Du L, Liu X, Jing J, Zhao X, et al. Serum levels of leptin, insulin, and lipids in relation to breast cancer in china. Endocrine. 2005;26:19-24.

25. Houseknecht KL, Mantzoros CS, Kuliawat R, Hadro E, Flier JS, Kahn BB. Evidence for leptin binding to proteins in serum of rodents and humans: Modulation with obesity. Diabetes. 1996;45:1638-43.

26. Ishikawa M, Kitayama J, Nagawa H. Enhanced expression of leptin and leptin receptor (OB-R) in human breast cancer. Clin Cancer Res. 2004;10:4325-31. 